\title{
Estimated Effects of Climate Variables on Transmission of Malaria, Dengue and \\ Leptospirosis within Georgetown, Guyana \\ C Boston, R Kurup
}

\begin{abstract}
Objective: To analyze meteorological data (temperature, rainfall and relative humidity) and vector borne diseases (malaria, dengue and leptospirosis) to determine trends that may exist between and among variables within the Georgetown area.

Design and Methods: This study took on a retrospective approach which used data from the Ministry of Health and Ministry of Agriculture, Hydro-meteorological Department to assess the true nature of the relationship between climate and vector borne diseases within Georgetown area. Correlation and regression analysis was done using SPSS 13 and JMP.

Results: The results yielded weak positive correlation between climate variables and vector borne disease with strongest correlation between $P$ falciparum and $P$ malariae. Leptospirosis showed positive correlation with humidity and dengue showed positive correlation with all three climate variables measured. Projections showed that with a $1^{\circ}$ increase in temperature, $1 \%$ increase in relative humidity and $50 \mathrm{~mm}$ increase in rainfall there were be significant increases in malaria and leptospirosis.

Conclusion: There has been theories that suggest a connection between climate variable and vector borne disease but conclusive evidence does not exist. In this present study the need for research that yields more unwavering results are highlight. There is no doubt that climate variables influence vector borne diseases. Therefore, it is recommended that an interdisciplinary approach be taken to ensure reliability and foster a better understanding between climate variables and vector borne disease.
\end{abstract}

Keywords: Dengue, Leptospirosis, Malaria, climate change

From: Faculty of Health Sciences, University of Guyana, Guyana.

Correspondence: Dr R Kurup, Faculty of Health Sciences, University of Guyana, Guyana.

E-mail: kurup_rajini@yahoo.com 


\section{INTRODUCTION}

Climate affect infectious disease that is transmitted via contaminated water or food. In poor countries, for instance, water related diseases are especially a problem because of inadequate sanitation. When floodwaters become contaminated with human and animal waste the occurrence and often outbreak of disease occurs e.g. Leptospirosis (1). It has already been established that a relationship exist between rainfall and disease spread by insect vectors which breed in water and as such are dependent on surface water availability. Natural disasters including floods, tsunamis, earthquakes, tropical cyclones (e.g., hurricanes and typhoons) and tornadoes have been secondarily described with the following infectious diseases including diarrheal diseases, acute respiratory infections, malaria, leptospirosis, measles, dengue fever, viral hepatitis, typhoid fever, meningitis, as well as tetanus and cutaneous mucormycosis (2).

Malaria is noted to be among the diseases listed as sensitive to climate change $(3,4)$. Dengue fever (DF) and dengue hemorrhagic fever (DHF) outbreaks occur in most tropical and subtropical regions and are the most important emerging arboviral diseases worldwide. The endemic area for dengue extends over 60 countries $(5,6)$. Leptospirosis is considered to be widespread in many tropical countries, including the Caribbean region and Central and South America $(7,8,9)$. Most often, the outbreaks have occurred after severe flooding due to increased contact with contaminated water $(10,11,12)$. In Guyana, leptospirosis has been detected in humans and livestock, but prior to 2005 , no outbreaks had been reported $(10,13,14,15)$. The 2005 floods in Guyana saw 34 deaths being attributed to leptospirosis (Dechet et al., 2012).

Diseases such as malaria and dengue are notably affected by such variations, as the mosquitos need access to stagnant water in order to breed. However, both wet and dry conditions favor mosquitos, example, heavy rains can create as well as wash away breeding sites while on 
the other hand droughts can lead to increase breeding sites by stagnant water accumulation. Vector-borne disease transmission is sensitive to temperature fluctuations also; increases in temperature reduce the time taken for vectors to breed. In addition, increase temperature also decrease the incubation period of the pathogen resulting in the vector becoming infectious in a shorter time (16). Climatic variations is seen as a major contributor to leptospirosis and because of the transmission routes, increase rainfall often times leads to increased human exposure (17) through both increased survival of the bacteria in the environment and increased exposure of humans to surface water (18). Extreme climatic events and floods have frequently been associated with leptospirosis outbreaks $(19,20)$. Rainfall also leads to larger rodent populations, further contributing to increased environmental contamination (21). This study therefore aims to identify relationship between climate variables and vector borne diseases.

\section{METHOD}

A retrospective approach was employed to gather information in relation to prevalence of malaria, dengue and leptospirosis as well as the three climate variables being investigated (temperature, rainfall and humidity). Data relating to temperature, rainfall and relative humidity was collected from the Ministry of Agriculture for 2009 to 2014. Ministry of Health provided information on the incidences of malaria, dengue and leptospirosis over the same time period. All statistical analysis was done using SPSS the Statistical Package for Social Sciences (SPSS) version 13. And JMP software. Permission to conduct this research was approved from Ethical Review Board of Ministry of Health. 


\section{RESULTS}

Data provided from Ministry of Agriculture for the study period of 2009 to 2014, revealed that there was a mean rainfall of $2309.63 \mathrm{~mm}$ with the highest amount of rainfall recorded in the year $2010(2565.2 \mathrm{~mm})$. Temperature showed a mean of $27.37^{\circ} \mathrm{C}$ with 2010 recording the highest temperature $\left(27.9^{\circ} \mathrm{C}\right)$. Whereas the highest recorded relative humidity was noted in 2009,2011 and 2013 (78\%). Relative humidity for the study period had a mean of $77.50 \%$ (Figs 1 and 2).

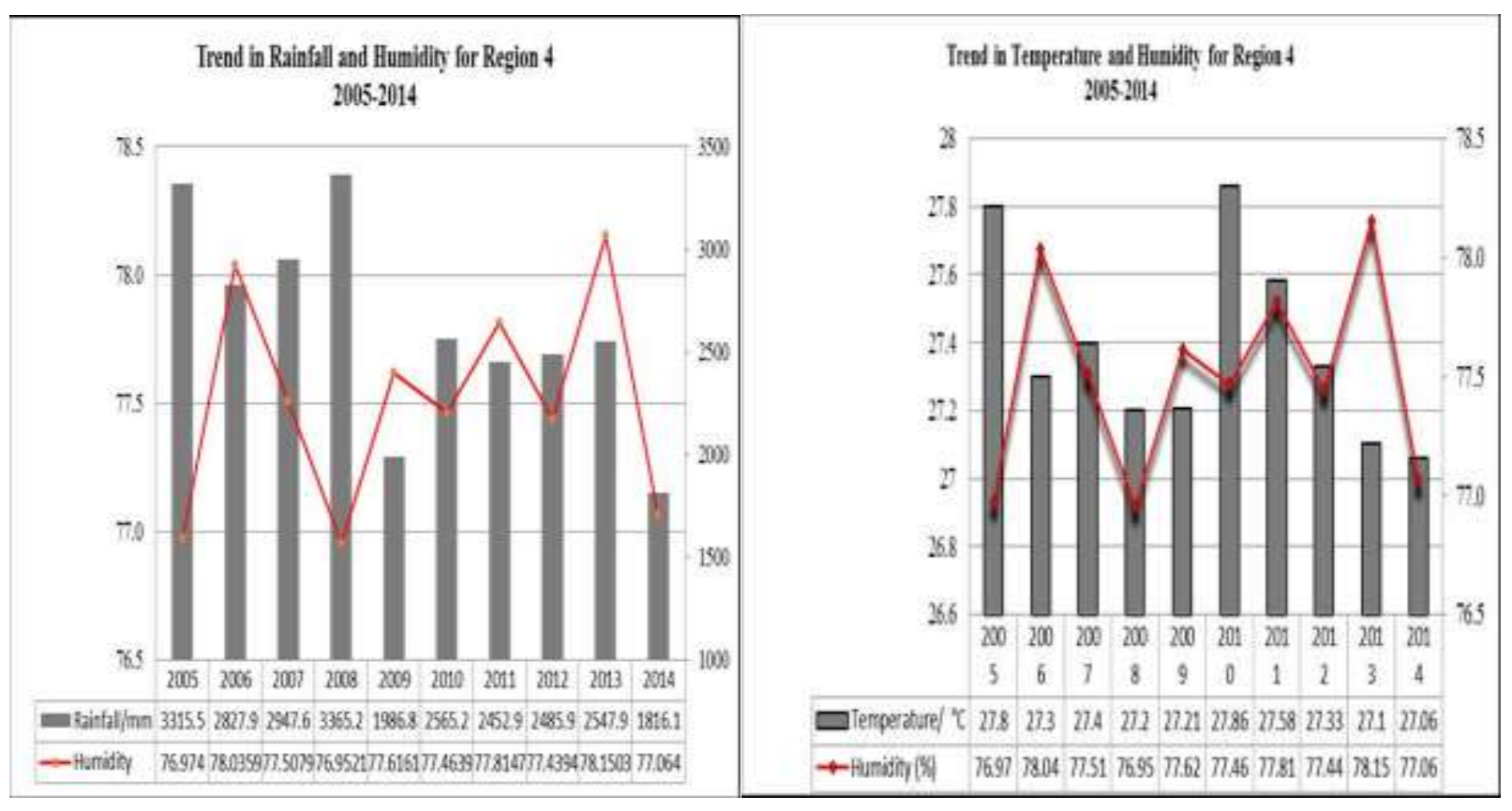

Figs: 1 and 2 Graphical representation of temperature, rainfall and humidity data. 


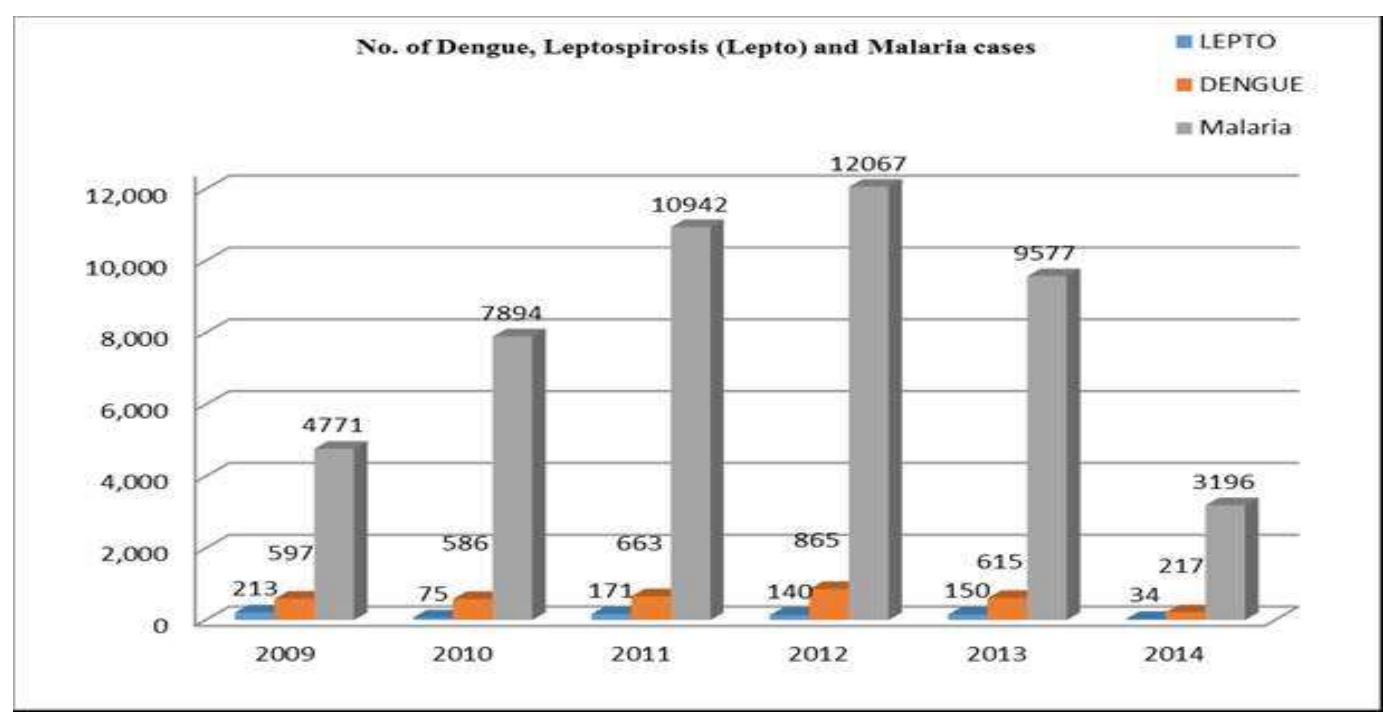

Fig. 3: Chart showing the total number of Dengue, Leptospirosis (Lepto) and Malaria cases for the period 2009-2014.

For each consecutive year, the incidence of malaria recorded the highest frequency followed by dengue and leptospirosis respectively. The highest annual total for malaria was recorded in 2012; in the same year, dengue recorded the highest frequency followed by leptospirosis in 2009 (Fig. 3). Incidences of dengue showed a weak positive correlation with humidity $(r=0.2)$ and temperature $(r=0.1)$. However, the strongest association was seen in relation to dengue incidences and rainfall $(\mathrm{r}=0.7)$ [Fig. 4]. The strongest relationship was noted between leptospirosis and humidity $\left(\mathrm{r}^{2}=0.6\right)$. Whereas, a negative relationship was observed between leptospirosis and rainfall $\left(\mathrm{r}^{2}=0.01\right)$ and leptospirosis and temperature $\left(\mathrm{R}^{2}=0.0001\right)$ [Fig. 5]. 


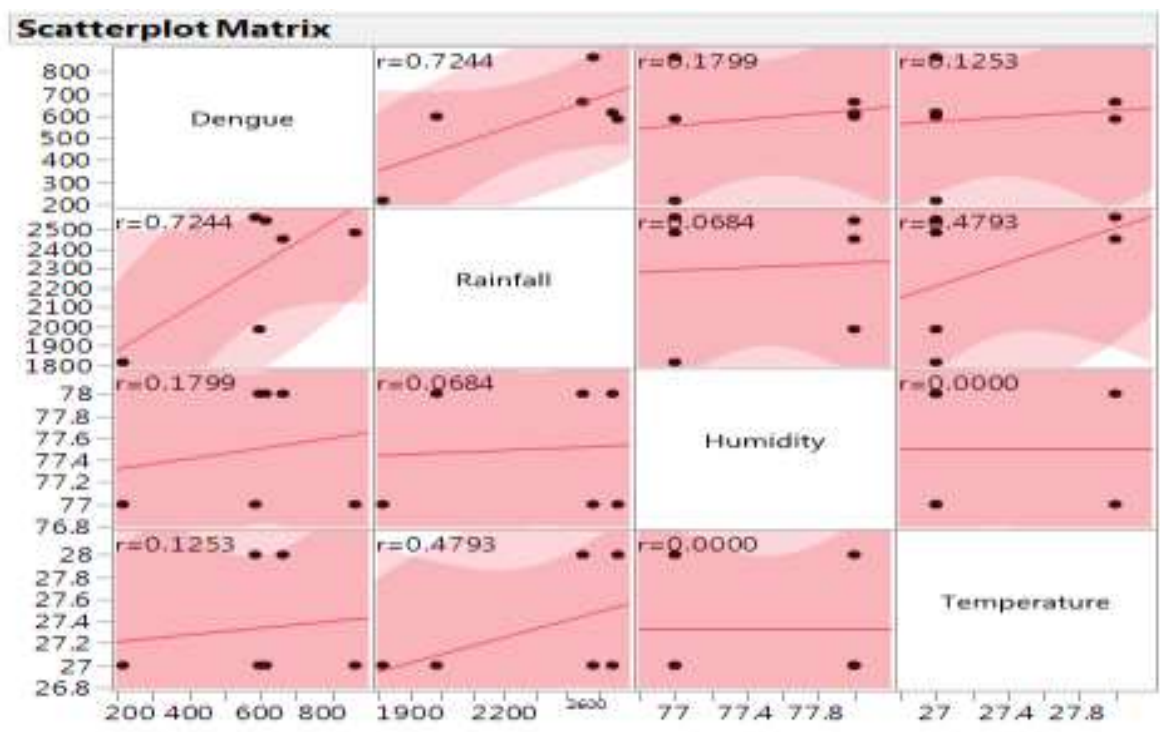

Fig. 4: Graphical comparison of dengue with rainfall, humidity and temperature.

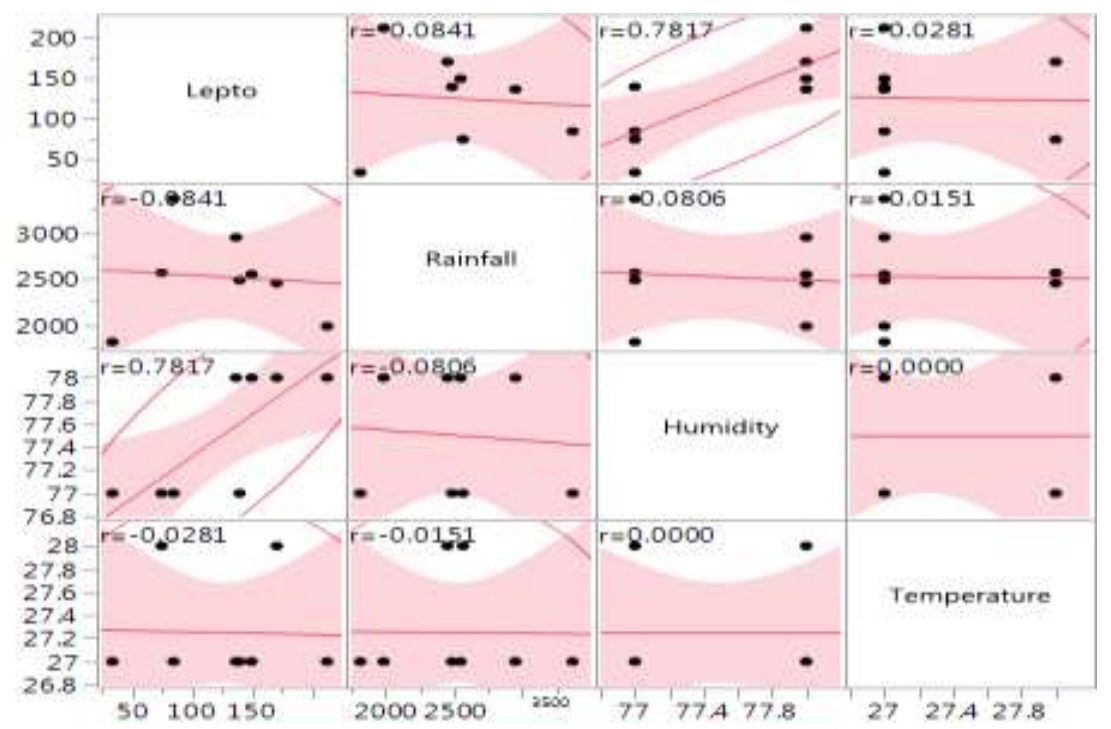

Fig. 5: Graphical comparison of Leptospirosis with rainfall, humidity and temperature. 


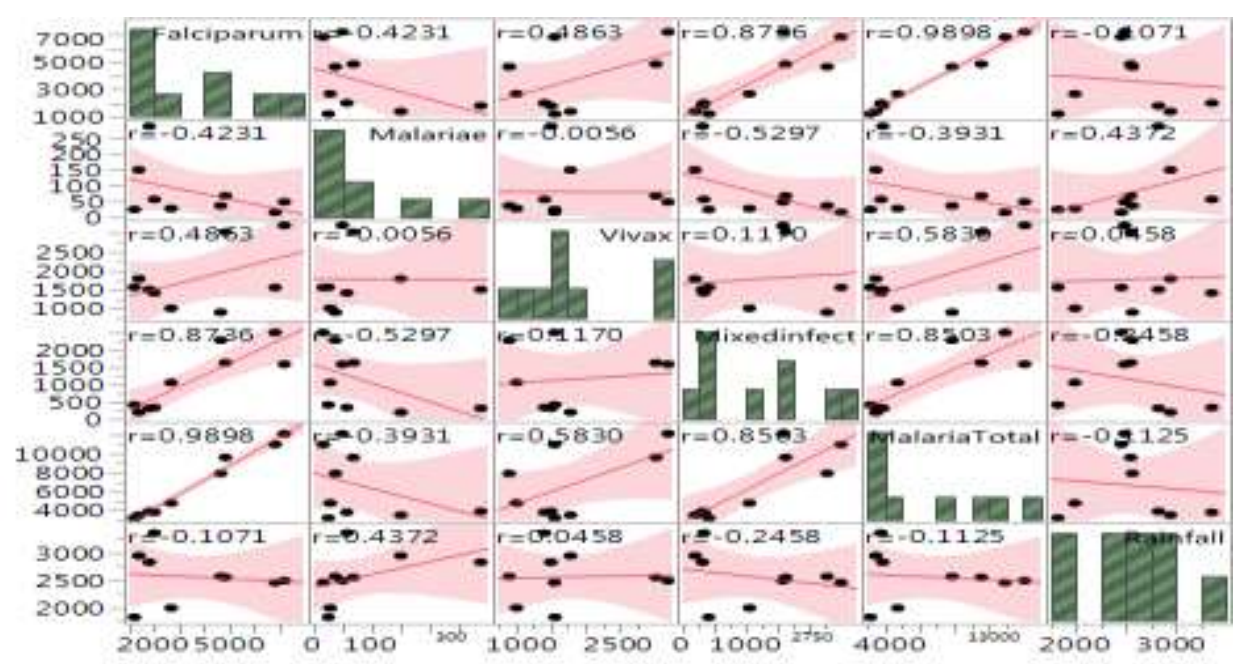

Fig. 6: Graphical comparison of malaria species with rainfall.

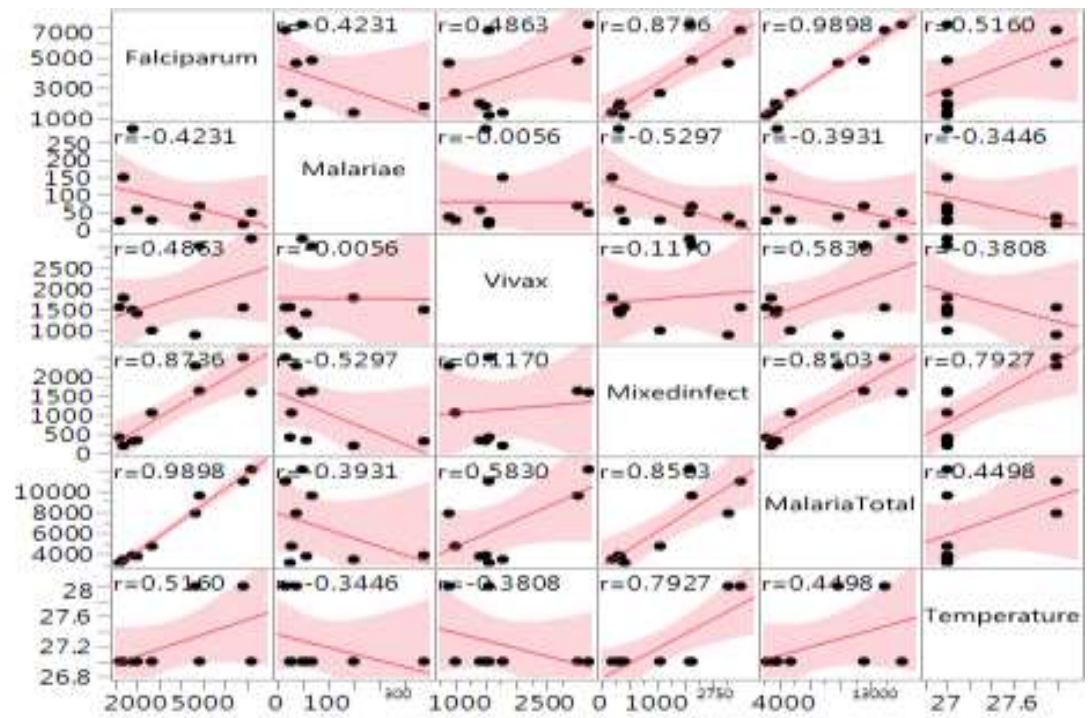

Fig. 7: Graphical comparison of malaria species with temperature. 


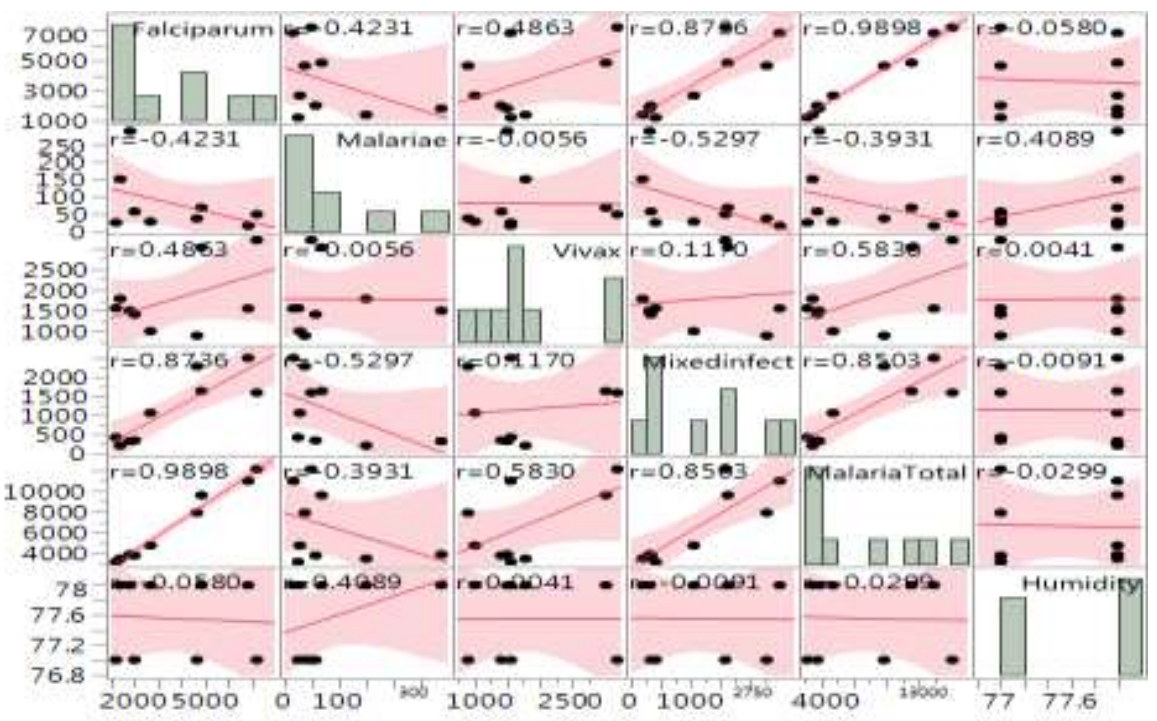

Fig. 8: Graphical comparison of malaria species with humidity.

\section{DISCUSSION}

This study have echoed the conclusion of most studies which suggest that either temperature or rainfall favors increase in dengue, specifically increase in rainfall. Scientific confirmation exist to show the relationship between climate variables, temperature and rainfall, and dengue (22, 23). Similar study done in singapore on incidences of dengue along with vector population in addition to climatic conditions showed that with increasing temperature incidence of dengue increases by $8-20$ weeks (24). Contrary to projections made for malaria, the data showed that with an increase of any of the climate variables there would be a decrease in the incidences of dengue.

The strongest relationship in our study was noted between leptospirosis and humidity and a negative relationship was observed between leptospirosis and rainfall and leptospirosis and 
temperature. This, however, goes contrary to other published studies which showed strong correlation between leptospirosis outbreaks and rainfall $(25,26))$. Humans become more exposed when environmental conditions, such as wet and hot, that favors Leptospira survival presist (27). A sharp decline in the total malaria incidences was seen after 2012, which showed the highest recorded incidence of malaria for the period. In addition, the prediction model used, illustrated considerable increases likely due to rainfall and humidity. However, it should be noted that climate variability does not entirely influence malaria transmission. Factors such as social, biological, vector control measures, ecological settings, study population, population immunity and drug resistance have very influential roles on malaria transmission (28). These information, however, were not used in this study, and lack of should not diminish their importance in truly understanding every dimension of malaria transmission in relation to climate variability. In addition, the data collected did not reflect whether the cases identified were duplicates as this can lend to the increase in recorded cases of each malaria. In addition, limited or lack of diagnostic capabilities in other regions could possibly account for the increase in total malaria cases.

\section{CONCLUSIONS}

In recent years, the ability to predict local and regional weather, in terms of accuracy, has rapidly been improve due to advances in technology. This has allowed a better understanding of the interaction between climate and the temporal-spatial distribution of vector borne diseases as well as stimulating research interest on epidemic prediction modeling. It is recommended that an interdisciplinary approach be taken to ensure reliability and foster a better understanding between climate variables and vector borne disease. 


\section{REFERENCES}

1. Intergovernmental Panel on Climate Change. IPCC (Intergovernmental Panel on Climate Change). Climate Change 2001: IPCC Third Assessment Report. Working Group II Impacts, Adaptation and Vulnerability. Cambridge: Cambridge University Press 2001.

2. Kouadio IK, Aljunid S, Kamigaki T, Hammad K, Oshitani H. Infectious disease following natural disasters: prevention and control measures. Expert Rev Anti Infect Ther 2012; 10: 95-104.

3. Haines A, Kovats RS, Campbell-Lendrum D, Corvalan C. Climate change and human health: impacts, vulnerability and mitigation. Lanclet 2006; 367: 2101-9.

4. Patz JA, Olson SH. Malaria risk and temperature influences from global climate change and local land use practices . Proc Natl Acad Sci USA 2006; 103: 5635-6.

5. Rasgon JL. Dengue fever: Mosquitoes attacked from within. Nature 2011; 476: 407-8.

6. Brady OJ, Gething PW, Bhatt S, Messina JP, Brownstein JS. Hoen AG et al. Refining the global spatial limits of dengue virus transmission by evidence-based consensus. PLoS Negl Trop Dis 2012; 6: 1760.

7. Center CE. Morbidity Review of Communicable Diseases in CAREC Member Countries, 1980-2005: Leptospirosis.CAREC/PAHO/WHO 2008.

8. White F, Hospedales CJ. Communicable disease control as a Caribbean public health priority. Bulletin PAHO 1994.

9. WHO (1999). Leptospirosis worldwide. World Health Organisation, Weekly Epidemiological Report. 
10. Gaynor K, Katz AR, Park SY, Nakata M, Clark TA, Effler PV. Leptopsirosis on Oahu: an outbreak associated with flooding of a university campus. Am J Trop Med Hyg 2007: 76: $882-5$.

11. Kawaguchi L, Sengkeopraseuth B, Tsuyuoka R, Koizumi N, Akashi H, Vongphrachanh P et al. Seroprevalence of leptopisrosis and risk factor analysis in flood prone rural areas in Lao PDR. Am J Trop Med Hyg 2008; 78: 957-61.

12. Ko Al, Galvao Reis M, Ribeiro Dourado CM, Johnson WD, Riley LW. Urban epidemic of severe leptopsirosis in Brazil. Salvador Leptospirosis study group. Lancet 1999; 354181: 820-5.

13. Motie A, Myers DM. Leptospirosis in sheep and goat in Guyana. Trop Anim Health Prod 1986: 18: 113-4.

14. Silverman MS, Aronson L, Eccles M, Eisenstat J, Gottesman M et al. Leptospirosis in febrile men ingesting Agouti paca in South America. Ann Trop Med Parasitol 2004; 98: $851-9$.

15. Myers DM, Ruiz A, Applewhaite L. Leptospiral agglutinins among cattle in the Republic of Guyana. Trop Anim Health Prod 1985; 17: 239-43.

16. MacDonald G. The epidemiology and control of malaria. Oxford: Oxford University Press. London, 1957: 201.

17. Coelho MSZS, Massad E. The impact of climate on Leptospirosis in Sao Paulo, Brazil. Int J Biometeorol 2012; 56: 233-41.

18. Sarkar U, Nascimento SF, Barbosa R, Martins R, Nuevo H, Kalafanos I et al. A population-based case-control investigation of risk factors for leptospirosis during an urban epidemic. Am J Trop Med Hyg 2002; 66: 605-10. 
19. Ko AI, Reis MG, Dourado CMR, Johnson WD, Riley LW. Urban epidemic of severe leptopsirosis in Brazil. Lancet 354; 820-5.

20. Amilasan AT, Ujiie M, Suzuki M, Salva E, Belo MCP, Koizumi N et al. Outbreak of Leptospirosis after Flood, the Philippines, 2009. Emerg Infect Dis 2012; 18: 91-4.

21. Perez J, Brescia F, Becam J, Mauron C, Goarant C. Rodent abundance dynamics and leptospirosis carriage in an area of hyper-endemicity in New Caledonia. PLoS Negl Trop Dis 2011; 5: e1361.

22. Watts DM, Burke DS, Harrison BA, Whitmire RE, Nisalak A. Effects on temperature on the vector efficiency of Aedes aegypti for dengue 2 virus. Am J Trop Med Hyg 1987; 36: $143-52$.

23. Focks DA, Brenner RJ, Hayes J, Daniels E. Transmission thresholds for dengue in terms of Aedes aegypti pupae per person with discussion of their utility in source reduction efforts. Am J Trop Med Hyg 2000; 62: 11-18.

24. Heng, B., Goh, K., \& Neo, K. (1998). Environmental temperature, Aedes aegypti house index and rainfall as predictors of annual epidemics of dengue fever and dengue haemorrhagic fever in Singapore. Singapore: Ministry of Environment.

25. Gaynor K, Katz AR, Park SY, Nakata M, Clark TA, Effler PV. Leptopsirosis on Oahu: an outbreak associated with flooding of a university campus. Am J Trop Med Hyg 2007; 76: $882-5$.

26. Cann KF, Thomas D, Salmon RL, Wyn-Jones AP, Kay D. Extreme water-related weather events and waterborne disease. Epidemiol Infect 2013; 141: 671-86. 
27. Perez J, Brescia F, Becam J, Mauron C, Goarant C. Rodent abundance dynamics and leptospirosis carriage in an area of hyper-endemicity in New Caledonia. PLoS Negl Trop 2011; 5: e1361.

28. McMicheal AJ, Martens WJM. The health impacts of global climate change: grasping with scenarios, predictive models and multiple uncertainies. Ecosystem Health 1995; 1: 23-33. 